\title{
Evaluation of the Diagnostic Performance of EU-TIRADS in Discriminating Benign from Malignant Thyroid Nodules: A Prospective Study in One Referral Center
}

\author{
Roussanka D. Kovatcheva Alexander D. Shinkov Inna D. Dimitrova \\ Ralitsa B. Ivanova Kalin N. Vidinov Radina S. Ivanova \\ Department of Endocrinology, Medical University of Sofia, Sofia, Bulgaria
}

\section{Keywords}

Thyroid nodules · Ultrasound · EU-TIRADS · Malignancy risk

\begin{abstract}
Background: Several thyroid societies have endorsed ultrasound (US) malignancy risk stratification systems for thyroid nodules and the recently released European Thyroid Imaging Reporting and Data System (EU-TIRADS) needs large prospective studies for validation. Objective: The purpose of our study was to evaluate the performance of EU-TIRADS in identifying thyroid nodules for fine-needle aspiration biopsy (FNAB) and its ability to reduce the number of unnecessary biopsies. Methods: This was a single-center prospective study. From August 2017 to September 2018, 783 consecutive patients with 1,000 thyroid nodules underwent US examination and US-guided FNAB. A total of 741 patients (median age 50 years; range, $15-87$ years; 649 females, 92 males) with 942 nodules (median largest diameter $14 \mathrm{~mm}$; range, 4-96 $\mathrm{mm}$ ) met the following inclusion criteria: (1) nodules with benign or malignant cytology - categories II and VI of the Bethesda System for Reporting Thyroid Cytopathology (BSRTC); (2) nodules with non-diagnostic and indeterminate cytology (BSRTC I, BSRTC III, and BSRTC IV), or suspicious for
\end{abstract}

malignancy (BSRTC V), if postoperative histology was present; (3) nodules classified as BSRTC I and BSRTC III with a repeat FNAB and conclusive cytology. Results: Of 942 nodules, 839 (89.1\%) were benign and 103 (10.9\%) were malignant. Nodules were classified as follows: EU-TIRADS $2-4.8 \%$, EUTIRADS 3 - 37.4\%, EU-TIRADS 4 - 25.2\%, and EU-TIRADS 5 $32.6 \%$. The malignancy rate in categories 2 to 5 was $0,0,3.8$, and $30.6 \%$, respectively. Sensitivity, specificity, positive predictive value (PPV), negative predictive value (NPV), and accuracy of EU-TIRADS with a cut-off set at category 5 were $91.3,74.6,30.6,98.6$, and 76.4\%, respectively. Diagnostic performance other than sensitivity and NPV was superior in nodules $\geq 10 \mathrm{~mm}$. FNAB number would be reduced by $53.4 \%$ if FNAB criteria were strictly applied. When the indication for FNAB was applied as test positivity, the estimated sensitivity, specificity, PPV, and NPV of EU-TIRADS were 69.9, 56.3, 16.4, and $93.8 \%$, respectively. Conclusion: EU-TIRADS provides effective malignancy risk stratification that can guide the selection of thyroid nodules for biopsy. The application of the guidelines criteria for FNAB in the clinical practice might reduce significantly the number of unnecessary FNAB.

(C) 2020 European Thyroid Association Published by S. Karger AG, Basel

\section{KARGER}

(C) 2020 European Thyroid Association

Published by S. Karger AG, Basel
Roussanka D. Kovatcheva

Department of Endocrinology, Medical University of Sofia 2, Zdrave str.

BG-1431 Sofia (Bulgaria)

roussanka_kov@yahoo.com 


\section{Introduction}

Thyroid nodules are a common clinical finding, usually asymptomatic. Epidemiologic studies report 19-68\% prevalence of thyroid nodules diagnosed with high-resolution ultrasound (US) in the general population [1]. It is important to discriminate benign from malignant nodules, since cancer prevalence is $7-15 \%$ of all nodules [2]. US-guided fine-needle aspiration biopsy (FNAB) with cytology has high sensitivity and specificity in differentiating benign from malignant nodules [3]. However, the overuse of FNAB leads to increasing healthcare costs, emotional stress for patients, and unnecessary diagnostic thyroid surgeries. Thus, FNAB should be recommended selectively [4]. Several US features have been consistently associated with increased malignancy risk. Remonti et al. [5] found that specificity of microcalcifications, irregular margins, non-oval shape, and marked hypoechogenicity in discriminating benign from malignant nodules was $87.8,83.1,96.6$, and $62.3 \%$, respectively. However, the reported sensitivity of the aforementioned US features in the same study was $39.5,50.5,26.7$, and $62.7 \%$, respectively [5]. Kim et al. [6] also found high rates of specificity for microcalcifications, irregular margins, non-oval shape, and marked hypoechogenicity $(85.8,83,92.5$, and $94.3 \%$, respectively) and low rates of sensitivity (59.2, $55.1,32.7$, and $26.5 \%$, respectively). Therefore, US malignancy risk stratification systems that incorporate multiple US features have been developed over the past decade. In 2009, Horvath et al. [7] first proposed US Thyroid Imaging Reporting and Data System (TIRADS) followed by Park et al. [8], Kwak et al. [9], and Russ et al. [10], who tried to improve the diagnostic performance and to facilitate the clinical use of TIRADS [11]. Over the past 6 years, several thyroid societies have endorsed US TIRADS, including the European Thyroid Association's EU-TIRADS in 2017 [2, 12-15].

EU-TIRADS assesses four equally weighted suspicious US features (marked hypoechogenicity, irregular shape, microcalcifications, and irregular margins) and defines 5 categories based on US patterns [15]. Thyroid gland without nodules is classified as EU-TIRADS 1 (normal). Cystic and spongiform nodules without suspicious US features are defined as EU-TIRADS 2 (benign); oval-shaped, hyper- and isoechoic nodules with smooth margins and no suspicious US features as EU-TIRADS 3 (low risk); mildly hypoechoic nodules with oval shape, smooth margins, and no suspicious US features as EU-TIRADS 4 (intermediate risk). Nodules having one or more suspicious US features, marked hypoechogenicity, irregular shape, microcalcifications, and irregular margins, are classified as EU-TIRADS 5 (high risk). The estimated risk of malignancy (ROM) in category 2 is close to zero, in category 3 , $2-4 \%$, in category $4,6-17 \%$, and in category $5,26-87 \%$. Unlike EU-TIRADS, the US malignancy risk stratification system of the American College of Radiology (ACRTIRADS) is score-based where points are assigned to selected US features [14]. In ACR-TIRADS, solid composition, macrocalcifications, and rim calcifications are considered relatively suspicious US features, while tallerthan-wide shape, extrathyroidal extension, and punctate echogenic foci are definitely associated with malignancy. For example, a solid isoechoic nodule with macrocalcification, classified as EU-TIRADS 3 (low risk) with ROM of $2-4 \%$, will be defined as moderately suspicious having ROM of 5-20\%. Each US risk stratification system gives different weight to the various US characteristics. The Korean Society of Thyroid Radiology TIRADS (K-TIRADS) emphasizes nodule solidity as a feature associated with malignancy [12]. Hence, a nodule with mixed composition and mild hypoechogenicity without suspicious US features is classified as low suspicion with estimated ROM of 3-15\%. EU-TIRADS, on the other hand, accentuates the importance of echogenicity and would assess the same nodule as intermediate risk but with similar ROM of $6-17 \%$. The ability of each TIRADS to classify nodules with different sonographic patterns is essential for the clinical practice. However, Lauria Pantano et al. [16] reported that the American Thyroid Association (ATA) US stratification system failed to classify $5 \%$ of nodules (e.g., isoechoic nodules with US suspicious features) with malignancy rate of $16.7 \%$. Consistent with these results, Grani et al. [17] found that $17.9 \%$ of the analyzed nodules could not be classified by the ATA system.

Several studies were aimed to validate the various TIRADS, mostly with retrospective design [18-20]. Large prospective studies are needed to similarly validate the recently released EU-TIRADS. Our purpose was to evaluate the performance of EU-TIRADS in identifying thyroid nodules for FNAB and its potential to reduce the number of unnecessary biopsies.

\section{Materials and Methods}

Subjects

From August 2017 to September 2018, 783 consecutive patients with 1,000 thyroid nodules underwent US examination and USguided FNAB in one academic referral center. The subjects were referred for FNAB by secondary care physicians - endocrinolo- 
gists, surgeons, and nuclear medicine specialists. Patients were prospectively enrolled and included in the analysis if they met the following criteria: (1) nodules with benign or malignant cytology - categories II and VI of the Bethesda System for Reporting Thyroid Cytopathology (BSRTC); (2) nodules with non-diagnostic and indeterminate cytology (BSRTC I, BSRTC III, and BSRTC IV), or suspicious for malignancy (BSRTC V), if postoperative histology was present; (3) nodules classified as BSRTC I and BSRTC III with a repeat FNAB and conclusive cytology. Nodules with nondiagnostic (BSRTC I), indeterminate (BSRTC III and BSRTC IV), or suspicious for malignancy cytology (BSRTC V) were excluded if they did not undergo thyroid surgery or repeat FNAB with conclusive result.

Ultrasound Examination and EU-TIRADS Classification

Thyroid US was performed by three endocrinologists (R.D.K., A.D.S., and R.B.I.), trained in the same unit and with more than 20 years of experience in thyroid sonography, with Aloka Prosound Alpha 7 device, using 7-13.3 MHz linear array transducer with color Doppler.

The following US features were evaluated: size, composition (solid, cystic, predominantly solid, predominantly cystic), echotexture (homogeneous, heterogeneous), echogenicity of the solid component (isoechoic, hyperechoic, mildly hypoechoic, or markedly hypoechoic), shape (oval or non-oval, i.e., taller than wide, taller than long), margins (smooth, ill-defined, irregular), and presence of microcalcifications. Some ancillary US features were also assessed, such as vascularity (type I, II, III), macrocalcifications (coarse, rim, eggshell), comet-tail artefacts.

The ROM was rated according to EU-TIRADS using internally developed standardized report where the nodules were classified into categories 2, 3, 4, or 5 [15].

EU-TIRADS guidelines recommend FNAB for category 5, nodules $>10$, or $<10 \mathrm{~mm}$ when suspicious lymph nodes are present; category 4 , nodules $>15 \mathrm{~mm}$; category 3 , nodules $>20 \mathrm{~mm}$. Category 2 nodules are not indicated for FNAB. The number of FNABs which did not meet the EU-TIRADS criteria was estimated.

\section{Ultrasound-Guided FNAB}

In each patient, the US examination and the US-guided FNAB were performed by the same endocrinologist. A capillary technique using 25-gauge needles was applied with 2-3 passes per nodule depending on visual smears quality. The material was stained with May-Grünwald-Giemsa and read by a pathologist (R.S.I.) with 20 years of experience in thyroid cytology, blinded to the US risk category of the nodules. The specimens were classified following the latest edition of BSRTC [3]. The nodule management complied with BSRTC guidelines, except for molecular testing, which was not available.

\section{Reference Standard Diagnosis}

BSRTC guidelines state malignancy risk in BSRTC II 0-3\% and in BSRTC VI 97-99\% [3]. Therefore, in our study, the reference standard diagnosis was based on cytology for BSRTC II nodules which were considered benign and BSRTC VI nodules, classified as malignant. Nodules with inconclusive cytology (BSRTC I, III, and IV) were classified as benign or malignant according to the postoperative histology or repeat FNAB results. Nodules with BSRTC V cytology were classified as malignant if confirmed by histology as reference standard diagnosis.

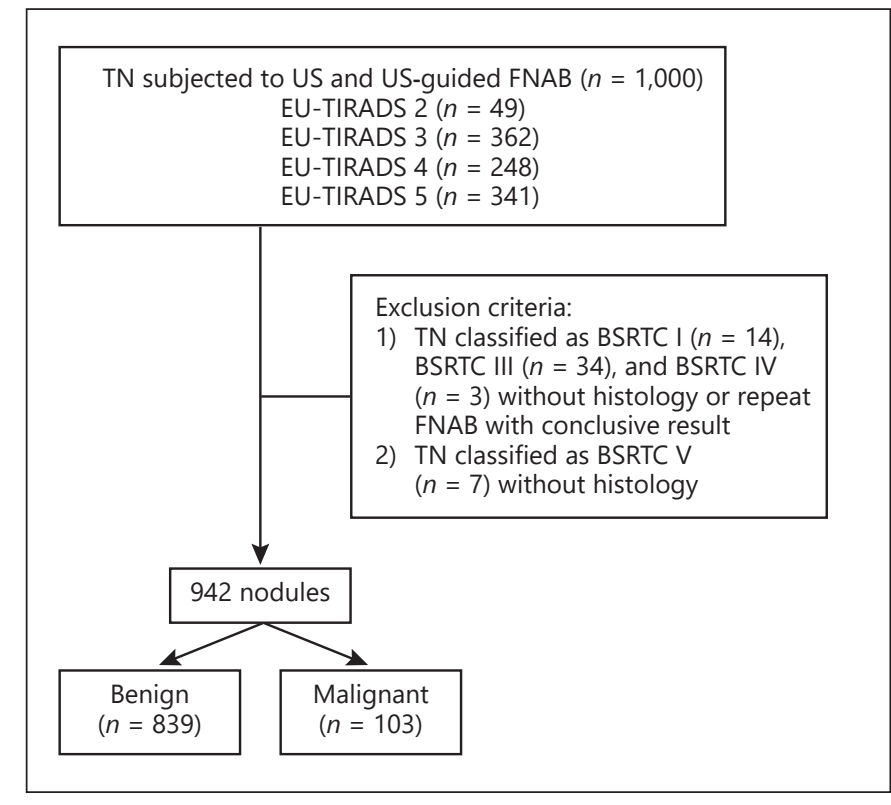

Fig. 1. Study design. TN, thyroid nodule; US, ultrasound; FNAB, fine-needle aspiration biopsy.

\section{Statistics}

Continuous variables were expressed as median and range. The Mann-Whitney $U$ test was used to estimate differences between continuous variables. Frequencies were compared by chi-square test. Receiver operating characteristic (ROC) curve analysis with area under the curve (AUC) set the optimal cut-off category discriminating benign from malignant nodules. EU-TIRADS categories 2, 3, and 4 were considered probably benign and category 5 , probably malignant. Based on the reference standard, true positive (TP), false positive (FP), true negative (TN), and false negative (FN) results were identified. Sensitivity, specificity, positive predictive value (PPV), negative predictive value (NPV), and diagnostic accuracy were calculated in accordance with the predictive value model proposed by Galen [21]. We also estimated the diagnostic performance of EU-TIRADS adopting the EU-TIRADS guidelines' indications for FNAB as test positivity. Then the indication for FNAB was compared to the reference standard (benign vs. malignant) and TP, FP, TN, and FN cases were defined. The 95\% confidence interval (CI) of all estimates was identified. $p \leq$ 0.05 was considered statistically significant. Statistical analysis was performed using SPSS 19.0 (SPSS Inc., Chicago, IL, USA).

\section{Results}

\section{Characteristics of Patients}

A total of 1,000 nodules were subjected to US risk stratification and US-guided FNAB. Twenty (2\%) nodules were classified as BSRTC I, 800 (80\%) as BSRTC II, $71(7.1 \%)$ as BSRTC III, 14 (1.4\%) as BSRTC IV, $46(4.6 \%)$ as BSRTC V, and 49 (4.9\%) as BSRTC VI. Fifty-eight nod- 
Table 1. Demographic data and nodule series features according to the reference standard diagnosis

\begin{tabular}{|c|c|c|c|c|}
\hline & All nodules & Benign & Malignant & $p$ value \\
\hline Total & $942(100)$ & $839(89.1)$ & $103(10.9)$ & \\
\hline Sex & & & & 0.014 \\
\hline Male & 113 & $93(82.3)$ & $20(17.7)$ & \\
\hline Female & 829 & $746(90.0)$ & $83(10.0)$ & \\
\hline Age, years ${ }^{\mathrm{a}}$ & $50(15-87)$ & $51(15-87)$ & $39(20-83)$ & $<0.001$ \\
\hline Nodules & & & & $<0.001$ \\
\hline Solitary & 241 & $199(82.6)$ & $42(17.4)$ & \\
\hline Multiple & 701 & $640(91.3)$ & $61(8.7)$ & \\
\hline Size, $\mathrm{mm}^{\mathrm{a}}$ & $14(4-96)$ & $14(4-90)$ & $12(5-96)$ & 0.111 \\
\hline
\end{tabular}

Unless otherwise indicated, data are presented as numbers. Data in parentheses are percentages. $p$ values are calculated using $\chi^{2}$ test. ${ }^{\text {a }}$ Data are presented as medians. Data in parentheses are ranges. $p$ values are calculated using Mann-Whitney $\mathrm{U}$ test.

ules defined as non-diagnostic $(n=14)$, indeterminate $(n=37)$, and suspicious for malignancy $(n=7)$ on cytology were excluded as no surgery or repeat FNAB with conclusive result were done.

Seven hundred forty-one subjects (649 females, 92 males, median age 50 years; range, 15-87 years) with 942 thyroid nodules (median largest diameter $14 \mathrm{~mm}$; range, 4-96 mm) were analyzed (Fig. 1) of which 839 (89.1\%) benign and 103 (10.9\%) malignant, with histological confirmation in 98 (95.2\%) of the malignant nodules. Five participants with BSRTC VI cytology refused surgery. The malignant histology comprised 94 papillary thyroid cancers, 1 medullary thyroid cancer, 1 poorly differentiated, 1 anaplastic, and 1 metastatic esophageal cancer.

Patients with malignant nodules were younger than those with benign ones $(p<0.001)$, and male sex was associated with malignancy ( $p=0.014)$. There was no significant difference between the median largest diameter of benign and malignant nodules (14 mm; range, 4-90 $\mathrm{mm}$ vs. $12 \mathrm{~mm}$; range, $5-96 \mathrm{~mm}, p=0.111$ ) (Table 1 ).

\section{Correlation between EU-TIRADS and Reference \\ Standard Diagnosis}

The EU-TIRADS-based malignancy risk stratification demonstrated: EU-TIRADS 2 - 45 (4.8\%) nodules, EUTIRADS 3 - 352 (37.4\%) nodules, EU-TIRADS 4 - 238 (25.2\%) nodules, and EU-TIRADS 5 - 307 (32.6\%) nodules. The malignancy rate was: $0 \%(0)$ in category $2,0 \%$ (0) in category $3,3.8 \%$ (9) in category 4 , and $30.6 \%$ (94)

Diagnostic Performance of EU-TIRADS
Table 2. Malignancy rates in EU-TIRADS categories according to the reference standard diagnosis in our series

\begin{tabular}{lccll}
\hline Risk category & $\begin{array}{l}\text { Total, } \\
n\end{array}$ & $\begin{array}{l}\text { Benign, } \\
n(\%)\end{array}$ & $\begin{array}{l}\text { Malignant, } \\
n(\%)\end{array}$ & $\begin{array}{l}\text { Estimated } \\
\text { MR, \% }\end{array}$ \\
\hline EU-TIRADS 2 & 45 & $45(100)$ & $0(0)$ & 0 \\
EU-TIRADS 3 & 352 & $352(100)$ & $0(0)$ & $2-4$ \\
EU-TIRADS 4 & 238 & $229(96.2)$ & $9(3.8)$ & $\begin{array}{c}\text { a } \\
\text { EU-TIRADS 5 }\end{array}$ \\
\hline
\end{tabular}

a Suggested malignancy risk range in the EU-TIRADS guidelines. EU-TIRADS, European Thyroid Imaging Reporting and Data System.

in category 5 (Table 2). The malignancy rate in EU-TIRADS 5 was significantly higher than in EU-TIRADS 4 ( $3.8 \%$ vs. $30.6 \%, p<0.001)$. When analyzed separately, all suspicious US features assessed in EU-TIRADS were more prevalent in malignant than in benign nodules $(p<$ 0.001 ) except mild hypoechogenicity $(p=0.661)$ (Table $3)$.

\section{Diagnostic Value of EU-TIRADS}

ROC curve analysis showed AUC of 0.850 (95\% CI, $0.82-0.88$ ) and set the EU-TIRADS 5 category as the optimal cut-off differentiating benign from malignant nodules. TP cases were EU-TIRADS 5 nodules with malignant diagnosis and FP cases, category 5 nodules with benign diagnosis. TN cases were EU-TIRADS 2, 3, or 4 nodules with benign diagnosis and FN cases, nodules in categories 2, 3, or 4 with malignant diagnosis. The diagnostic performance of EU-TIRADS with a cut-off set at category 5 in our study was: sensitivity $91.3 \%(94 / 103)$, specificity $74.6 \%$ (626/839), PPV 30.6\% (94/307), NPV $98.6 \%$ (626/635), and diagnostic accuracy $76.4 \%$ (720/942).

We also calculated the diagnostic performance of EUTIRADS recommendations adopting the indication for FNAB as test positivity. Nodules with benign reference standard were classified as TN when FNAB was not indicated. Malignant nodules which met the criteria for FNAB were considered TP. Nodules with benign reference standard when FNAB was indicated were classified as FP and malignant nodules were considered FN if they did not meet the FNAB criteria. The estimated sensitivity, specificity, PPV, and NPV ofEU-TIRADS were 69.9\% (72/103), $56.3 \%$ (472/839), 16.4\% (72/439), and 93.8\% (472/503), respectively. 
Table 3. US features of the nodules according to the reference standard diagnosis

\begin{tabular}{|c|c|c|c|c|c|c|}
\hline US feature & $\begin{array}{l}\text { Total } \\
(n=942)\end{array}$ & $\begin{array}{l}\text { Benign nodules } \\
(n=839)\end{array}$ & $\begin{array}{l}\text { Malignant nodules } \\
(n=103)\end{array}$ & $\begin{array}{l}\text { Positive LR } \\
(95 \% \mathrm{CI})\end{array}$ & $\begin{array}{l}\text { Negative LR } \\
(95 \% \text { CI })\end{array}$ & $p$ value \\
\hline \multicolumn{7}{|l|}{ Echogenicity } \\
\hline Hyperechoic/isoechoic* & $418(44.4)$ & $417(49.7)$ & $1(1.0)$ & $51.2(7.3-360.4)$ & $0.51(0.5-0.6)$ & $<0.001$ \\
\hline Mildly hypoechoic ${ }^{\dagger}$ & $357(37.9)$ & $320(38.1)$ & $37(35.9)$ & $0.94(0.7-1.2)$ & $1.04(0.9-1.2)$ & 0.661 \\
\hline Markedly hypoechoic ${ }^{\dagger}$ & $159(16.9)$ & $94(11.2)$ & $65(63.1)$ & $5.63(4.4-7.2)$ & $0.42(0.3-0.5)$ & $<0.001$ \\
\hline Solid $^{\dagger}$ & $681(72.3)$ & $584(69.6)$ & $97(94.2)$ & $1.35(1.3-1.4)$ & $0.19(0.1-0.4)$ & $<0.001$ \\
\hline Mixed cystic and solid* & $216(22.9)$ & $210(25.0)$ & $6(5.8)$ & $4.30(2.0-9.4)$ & $0.80(0.8-0.9)$ & $<0.001$ \\
\hline Cystic* & $8(0.8)$ & $8(1.0)$ & $0(0)$ & NA & $0.99(0.9-1.0)$ & 1.000 \\
\hline Spongiform* & $37(4.0)$ & $37(4.4)$ & $0(0)$ & NA & $0.96(0.9-1.0)$ & 0.027 \\
\hline \multicolumn{7}{|l|}{ Echotexture } \\
\hline Homogeneous $^{\dagger}$ & $685(72.7)$ & $602(71.8)$ & $83(80.6)$ & $1.12(1.0-1.3)$ & $0.69(0.5-1.0)$ & 0.058 \\
\hline None* & $706(75.0)$ & $674(80.3)$ & $32(31.1)$ & $2.59(1.9-3.5)$ & $0.29(0.2-0.3)$ & $<0.001$ \\
\hline \multicolumn{7}{|l|}{ Margins } \\
\hline Smooth* & $812(86.2)$ & 775 (92.4) & $37(35.9)$ & $2.57(2.0-3.3)$ & $0.12(0.1-0.2)$ & $<0.001$ \\
\hline Irregular $^{\dagger}$ & $130(13.8)$ & $64(7.6)$ & $66(64.1)$ & $8.40(6.4-11.1)$ & $0.39(0.3-0.5)$ & $<0.001$ \\
\hline \multicolumn{7}{|l|}{ Shape } \\
\hline Oval* & $814(86.4)$ & $764(91.1)$ & $50(48.5)$ & $1.88(1.5-2.3)$ & $0.17(0.1-0.2)$ & $<0.001$ \\
\hline Non-oval ${ }^{\dagger}$ & $128(13.6)$ & $75(8.9)$ & $53(51.5)$ & $5.76(4.3-7.7)$ & $0.53(0.4-0.7)$ & $<0.001$ \\
\hline \multicolumn{7}{|l|}{ Vascularity } \\
\hline Type I/II* & $813(86.3)$ & 747 (89.0) & $66(64.1)$ & $1.39(1.2-1.6)$ & $0.31(0.2-0.4)$ & $<0.001$ \\
\hline Type III $^{\dagger}$ & $129(13.7)$ & $92(11.0)$ & $37(35.9)$ & $3.28(2.4-4.5)$ & $0.72(0.6-0.8)$ & $<0.001$ \\
\hline
\end{tabular}

Data in parentheses are percentages. $p$ values are calculated using $\chi^{2}$ test and Fisher's exact test. Positive likelihood ratio $($ LR $)=$ sensitivity/1 - specificity; negative LR = 1 - sensitivity/specificity. Oval shape = oval or round shape; non-oval shape = taller-than-wide or taller-than-long shape. ${ }^{\dagger}$ Diagnostic parameters of the US features to predict malignant nodules: the presence of the US feature in a malignant nodule was considered true positive case and the absence in a benign nodule, true negative case when sensitivity and specificity were calculated. * Diagnostic parameters of the US features to predict benign nodules: the presence of the US feature in a benign nodule was considered true positive case and the absence in a malignant nodule, true negative case when sensitivity and specificity were calculated. US, ultrasound; NA, not applicable.

\section{EU-TIRADS Criteria for FNAB and Rate of Unnecessary Biopsies}

Our series included $675(71.7 \%)$ nodules $\geq 10 \mathrm{~mm}$ and $267(28.3 \%)<10 \mathrm{~mm}$. The subcentimeter nodules were distributed as follows: 7 (2.6\%) in EU-TIRADS 2, 41 (15.3\%) in EU-TIRADS 3, 88 (33.0\%) in EU-TIRADS 4, and 131 (49.1\%) in EU-TIRADS 5.

Four hundred thirty-nine nodules met the EU-TIRADS size criteria for FNAB of EU-TIRADS guidelines, including 15 EU-TIRADS 5 nodules $<10 \mathrm{~mm}$ with suspicious lymph nodes. Five hundred and three nodules did not meet the criteria for FNAB: $45 / 45$ (100\%) in EU-TIRADS 2, 203/352 (57.7\%) in EU-TIRADS 3, 139/238 (58.4\%) in EU-TIRADS 4, and 116/307 (37.8\%) in EUTIRADS 5. Thirty-one (6.2\%) of them were malignant.
Twenty-three $(74.2 \%)$ of the 31 malignant nodules were classified as EU-TIRADS 5 and $8(25.8 \%)$ as EU-TIRADS $4 ; 26(83.9 \%)$ were $<10 \mathrm{~mm}$ and $5(16.1 \%)$ were $\geq 10 \mathrm{~mm}$.

FNAB number would have been reduced by $53.4 \%$ (503/942) if FNAB criteria were strictly applied. The exclusion of the 267 subcentimeter nodules would reduce the FNAB number by $37.2 \%(251 / 675)$ and change the sensitivity, specificity, PPV, and NPV of EU-TIRADS (with a cut-off set at category 5 ) for nodules $\geq 10 \mathrm{~mm}$ to 98.4, 68.6, 35.8, and 99.6\%, respectively.

We evaluated the impact of nodule size on the diagnostic performance of EU-TIRADS in the whole nodule series and set a cut-off size of $10 \mathrm{~mm}$. The specificity, PPV, and accuracy were significantly better in nodules $\geq 10 \mathrm{~mm}$ than those $<10 \mathrm{~mm}$ (Table 4 ). 
Table 4. Diagnostic parameters of EU-TIRADS according to the nodule size in the whole nodule series

\begin{tabular}{llllc}
\hline $\begin{array}{l}\text { Diagnostic } \\
\text { performance }\end{array}$ & All nodules & $\geq 10 \mathrm{~mm}$ & $<10 \mathrm{~mm}$ & $p$ value $^{\mathrm{a}}$ \\
\hline Sensitivity, \% & 91.3 & 91.3 & 91.2 & $\mathrm{NS}$ \\
Specificity, \% & 74.6 & 81.4 & 57.1 & $<0.001$ \\
PPV, \% & 30.6 & 35.8 & 23.7 & 0.01 \\
NPV, \% & 98.6 & 98.8 & 97.8 & NS \\
Accuracy, \% & 76.4 & 82.4 & 61.4 & $<0.001$ \\
\hline
\end{tabular}

Values are presented as percentages. ${ }^{\mathrm{a}} p$ value from comparison of the diagnostic parameters of EU-TIRADS according to nodule size. True positive cases were considered EU-TIRADS 5 nodules with malignant reference standard. True negative cases were considered EU-TIRADS 2, 3, or 4 nodules with benign reference standard. EU-TIRADS, European Thyroid Imaging Reporting and Data System; NS, not significant.

\section{Discussion}

In our prospective study, we evaluated the diagnostic performance of EU-TIRADS in a series of 942 consecutive nodules referred for FNAB. We found that EU-TIRADS was able to rule out malignancy with high probability (NPV, 98.6\%). Malignancy rates in EU-TIRADS 4 and EU-TIRADS 5 categories were close to the lower limit of the range cited in the guidelines (3.8 and 30.6\% vs. 6 and 26\%, respectively) [15]. Our results are similar to those reported by Maino et al. [22] in a prospective validation study of EU-TIRADS with cytology as reference standard. In contrast, the malignancy rate found in some retrospective studies was close to the upper limit of the range cited in the guidelines [18, 20,23]. Cancer prevalence in these series was much higher than in ours $-18.1,40.8$, and $24.3 \%$ vs. $10.9 \%$ respectively, due to the predominant use of histology as a reference standard.

We did not find any malignancy in EU-TIRADS 2 and 3 categories. Our results are in agreement with the EUTIRADS guidelines not recommending FNAB for category 2.

In our histological series there was no case of follicular thyroid cancer. The majority of histologically confirmed malignancies were papillary thyroid cancers (95.9\%). We should emphasize that the suspicious US features assessed in EU-TIRADS are highly specific for papillary thyroid cancer, but are not validated for follicular thyroid cancer, which frequently has low-risk US appearance [24, 25].

Diagnostic Performance of EU-TIRADS
The ROC curve analysis in our study set EU-TIRADS 5 as the optimal cut-off to discriminate between benign and malignant nodules, which is in agreement with the findings of Xu et al. [20]. Maino et al. [22] reported that EU-TIRADS 4 was not able to predict malignancy. Nodule echogenicity is an essential feature assessed by EUTIRADS and mild hypoechogenicity is sufficient to define an intermediate malignancy risk, even in cases of mixed composition. In our study, mild hypoechogenicity prevalence was similar in benign and malignant lesions, which is in agreement with the results of Tugendsam et al. [26] and Ha et al. [27], but in contrast to those reported in the prospective study by Russ et al. [10]. Moreover, interobserver agreement on nodule echogenicity, reported in the literature, has been quite low [28, 29]. Thus, methods for quantitative measurement of echogenicity as well as various approaches aiming to improve the overall reproducibility and diagnostic accuracy of US stratification systems have been sought [30, 31]. Grani et al. [30] did a gray-scale analysis of 908 nodules and found that nodule/parenchyma gray ratio could quantify the degree of hypoechogenicity. Another study based on a large nodule series reported that the first commercially available computer-aided diagnosis system was able to rule out malignancy with high probability [31]. Nevertheless, the computer-aided diagnosis system showed lower specificity and PPV than the clinical expert [31]. In our study, the diagnostic value of mild hypoechogenicity, as a single marker of malignancy, was insufficient and we consider that it should be supported by additional US characteristics, such as vascularity or elasticity $[10,15]$.

The sensitivity, specificity, PPV, and NPV in our study were $91.3,74.6,30.6$, and $98.6 \%$, respectively. Trimboli et al. [23] reported similar sensitivity (93\%) and specificity (67.9\%), but higher PPV (48.2\%) and similar NPV (96.8\%) with a cut-off set at EU-TIRADS $>3$. A possible explanation of these differences could be the variable proportion of malignant nodules in the study population. The study by Trimboli et al. was retrospective with histology as reference standard and high malignancy rate (24.3\%) [23]. The lower rate of malignant nodules in our study probably affects the PPV. Nevertheless, both studies showed that EU-TIRADS was able to rule out malignancy with high probability (NPV, $98.6 \%$ in our series and $96.8 \%$ in Trimboli's series) [23]. Maino et al. [22] reported similar NPV of $98.8 \%$.

We found that nodule size had an impact on EU-TIRADS diagnostic performance. Specificity, PPV, and accuracy were significantly better for nodules $\geq 10 \mathrm{~mm}$. These results are in contrast to Trimboli et al. [23], who 
Table 5. Characteristics of different studies investigating the diagnostic performance of EU-TIRADS in selecting thyroid nodules for FNAB

\begin{tabular}{|c|c|c|c|c|c|c|c|c|c|}
\hline $\begin{array}{l}\text { Author, } \\
\text { year }\end{array}$ & $\begin{array}{l}\text { Included } \\
\text { centers*, } n\end{array}$ & $\begin{array}{l}\text { Study } \\
\text { design* }\end{array}$ & $\begin{array}{l}\mathrm{TN}, \\
n^{*}\end{array}$ & Reference standard* & $\begin{array}{l}\text { Cancer } \\
\text { rate* }^{*}\end{array}$ & $\begin{array}{l}\text { Sensitivity* } \\
(95 \% \mathrm{CI})\end{array}$ & $\begin{array}{l}\text { Specificity* } \\
(95 \% \mathrm{CI})\end{array}$ & $\begin{array}{l}\mathrm{PPV}^{*} \\
(95 \% \mathrm{CI})\end{array}$ & $\begin{array}{l}\mathrm{NPV}^{*} \\
(95 \% \mathrm{CI})\end{array}$ \\
\hline $\begin{array}{l}\text { Present } \\
\text { study, } 2020\end{array}$ & 1 & PCS & 942 & $\begin{array}{l}\text { (a) FNAB - TN with conclusive cytology } \\
\text { (BSRTC II and BSRTC VI) }\end{array}$ & 10.9 & $\begin{array}{l}69.9 \\
(60.1-78.6)\end{array}$ & $\begin{array}{l}56.3 \\
(52.8-59.7)\end{array}$ & $\begin{array}{l}16.4 \\
(14.5-18.5)\end{array}$ & $\begin{array}{l}93.8 \\
(91.9-95.4)\end{array}$ \\
\hline
\end{tabular}

(b) Histological diagnosis or repeat FNAB -

$\begin{array}{llll}(60.1-78.6) & (52.8-59.7) & (14.5-18.5) & (91.9-95.4)\end{array}$

TN with inconclusive cytology (BSRTC I,

BSRTC III, and BSRTC IV) and subsequent

histology or repeat FNAB with conclusive

cytology

(c) Histological diagnosis - suspicious for

malignancy TN on cytology (BSRTC V)

which underwent surgery

\begin{tabular}{|c|c|c|c|c|c|c|c|c|c|}
\hline $\begin{array}{l}\text { Grani et } \\
\text { al., } 2019\end{array}$ & 1 & PCS & 502 & $\begin{array}{l}\text { (a) FNAB - TN with conclusive cytology } \\
\text { (TIR2, TIR4, TIR5 corresponding to }\end{array}$ & 7.2 & $\begin{array}{l}86.1 \\
(70.5-95.3)\end{array}$ & $\begin{array}{l}32.0 \\
(27.8-36.4)\end{array}$ & $\begin{array}{l}8.9 \\
(6.1-12.4)\end{array}$ & $\begin{array}{l}96.7 \\
(92.6-98.9)\end{array}$ \\
\hline
\end{tabular}

[17] BSRTC II, BSRTC V, and BSRTC VI)

(b) Histological diagnosis or repeat FNAB -

TN with inconclusive cytology (TIR1,

TIR3A, and TIR3B corresponding to

BSRTC I, BSRTC III, and BSRTC IV) and

subsequent histology or repeat FNAB with

conclusive cytology

\begin{tabular}{|c|c|c|c|c|c|c|c|c|c|}
\hline $\begin{array}{l}\text { Trimboli } \\
\text { et al., } \\
2019 \text { [23] }\end{array}$ & 3 & RCS & 1,058 & Histological diagnosis & 24.3 & $\begin{array}{l}67.0 \\
(60.4-72.3)\end{array}$ & $\begin{array}{l}63.0 \\
(59.5-66.3)\end{array}$ & $\begin{array}{l}36.5 \\
(33.7-39.5)\end{array}$ & $\begin{array}{l}85.4 \\
(83.0-87.5)\end{array}$ \\
\hline $\begin{array}{l}\text { Xu et al., } \\
2018 \text { [20] }\end{array}$ & 3 & RCS & 2,465 & $\begin{array}{l}\text { (a) FNAB - TN with BSRTC II cytology } \\
\text { and subsequent US follow-up } \\
\text { (b) Histological diagnosis - TN with } \\
\text { postoperative histology }\end{array}$ & 40.8 & $\begin{array}{l}50.0 \\
(46.4-52.7)\end{array}$ & $\begin{array}{l}57.4 \\
(54.8-60.0)\end{array}$ & $\begin{array}{l}44.5 \\
(42.4-46.6)\end{array}$ & $\begin{array}{l}62.3 \\
(60.5-64.1)\end{array}$ \\
\hline
\end{tabular}

Values are presented as percentages. * The data were extracted from the original articles. Nodules with malignant reference standard which met the EUTIRADS criteria for FNAB were considered true positive cases. Nodules with benign reference standard which did not meet the EU-TIRADS criteria for FNAB were considered true negative cases. EU-TIRADS, European Thyroid Imaging Reporting and Data System; FNAB, fine-needle aspiration biopsy; TN, thyroid nodule; PCS, prospective cohort study; RCS, retrospective cohort study; BSRTC, Bethesda System for Reporting Thyroid Cytopathology; TIR, Italian Consensus for Thyroid Cytopathology.

reported equivalent diagnostic parameters for nodules $<10 \mathrm{~mm}$ and $\geq 10 \mathrm{~mm}$. However, in the series of Moon et al. [32], the specificity, NPV, and accuracy of the grayscale US features were significantly higher in nodules $>10$ mm compared to smaller lesions. Cheng et al. [33] and Xu et al. [34] also reported that TIRADS model of thyroid nodules was less reliable in smaller lesions. Similar findings were reported in a retrospective multicenter study by Ha et al. [27], where subcentimeter benign nodules showed more frequently suspicious US features than larger benign nodules.

The application of EU-TIRADS guidelines would reduce the number of FNAB in our series by $53.4 \%$, which is in agreement with some recently reported data $[20,22$, 23]. However, Grani et al. [17] found lower FNAB reduction $(30.7 \%)$ probably due to their study design which excluded subcentimeter nodules. The exclusion of sub- centimeter nodules from our study would reduce the number of FNAB by $37.2 \%$ and increase the sensitivity, PPV, and NPV of EU-TIRADS to 98.4, 35.8, and 99.6\%, respectively.

The cumulative malignancy rate for nodules not meeting the FNAB criteria in our study was $6.2 \%$ and is slightly higher than that reported by Maino et al. [22] (3.6\%) and Grani et al. [17] (3.2\%). However, Trimboli et al. [23] would miss larger portion of carcinomas (25.6\%), which could be explained with the surgical recruitment and high malignancy rate in their study. Despite the different results, the clinical significance of omitting small papillary carcinomas without concomitant lymph node metastases and extrathyroidal extension is still controversial due to their indolent behavior.

By adopting the indication for FNAB as test positivity we found that EU-TIRADS was able to identify nodules 
with low malignancy risk whose FNAB could be safely avoided (NPV of 93.8\%). A recent meta-analysis by Castellana et al. [35] investigating the efficiency of the five most common US stratification systems (American Association of Clinical Endocrinologists/American College of Endocrinology/Associazione Medici Endocrinologi [AACE/ACE/AME] system, ACR-TIRADS, ATA system, EU-TIRADS, K-TIRADS) to correctly select thyroid nodules for FNAB reported a substantial heterogeneity of all summary operating points with the exception of NPV, which was high in almost every study [35]. Since the disease prevalence and study design could have an influence on the diagnostic parameters of EU-TIRADS, we compared our results with those of three other studies investigating the diagnostic value of EU-TIRADS (Table 5). The sensitivity of EU-TIRADS for selecting nodules for FNAB in our study was $69.9 \%$, which is close to the results of Trimboli et al. [23], but lower than that reported by Grani et al. [17]. However, the exclusion of subcentimeter nodules in the design of Grani's study could decrease the number of FN cases, e.g., subcentimeter nodules not meeting FNAB criteria but harboring papillary microcarcinoma.

The main strength of our study is its prospective design and large number of nodules, recruited for a short period of time in one referral center with uniform US and cytological criteria. However, it has several limitations. First, we used a combination of cytology and histology as reference standard. With cytology alone as reference standard, FN results in BSRTC II nodules might have occurred. To avoid FP cases, we included only BSRTC V nodules with histologically confirmed malignancy. Second, the exclusion of 58 nodules with nondiagnostic, indeterminate, or suspicious cytology without conclusive reference standard might create a selection bias. Third, the US assessment of thyroid nodules was performed by three endocrinologists, with a possible interobserver variability. However, the high level of reproducibility of EUTIRADS reported in the literature [36], as well as the homogenous professional profile and experience of the specialists performing the US scans in our study, could have contributed to minor interobserver variability.

In conclusion, EU-TIRADS provides effective malignancy risk stratification that can guide the selection of thyroid nodules for biopsy. Applying the guideline criteria for FNAB in clinical practice, we should be able to reduce significantly the number of unnecessary FNAB.

\section{Statement of Ethics}

The study protocol was approved by the Institutional Review Board and all patients signed informed consent.

\section{Disclosure Statement}

The authors have no conflicts of interest to declare.

\section{Funding Sources}

This study did not receive any funding from commercial, institutional, or academic sources.

\section{Author Contributions}

R.D.K., A.D.S., and I.D.D. contributed to the design of the work, the acquisition, analysis and interpretation of data, and manuscript writing; R.B.I. and K.N.V: recruitment of subjects and data acquisition; R.S.I. performed the cytology and histology reports. All authors approved the final version of the manuscript.

\section{References}

1 Guth S, Theune U, Aberle J, Galach A, Bamberger CM. Very high prevalence of thyroid nodules detected by high frequency $(13 \mathrm{MHz})$ ultrasound examination. Eur J Clin Invest. 2009 Aug;39(8):699-706.

2 Haugen BR, Alexander EK, Bible KC, Doherty GM, Mandel SJ, Nikiforov YE, et al. 2015 American Thyroid Association management guidelines for adult patients with thyroid nodules and differentiated thyroid cancer: The American Thyroid Association Guidelines Task Force on Thyroid Nodules and Differentiated Thyroid Cancer. Thyroid. 2016 Jan;26(1):1-133.

3 Cibas ES, Ali SZ. The 2017 Bethesda System for Reporting Thyroid Cytopathology. J Am
Soc Cytopathol. 2017 Nov - Dec;6(6):21722.

4 Ahn HS, Kim HJ, Welch HG. Korea's thyroidcancer "epidemic" - screening and overdiagnosis. N Engl J Med. 2014 Nov;371(19):1765-7.

5 Remonti LR, Kramer CK, Leitão CB, Pinto LC, Gross JL. Thyroid ultrasound features and risk of carcinoma: a systematic review and meta-analysis of observational studies. Thyroid. 2015 May;25(5):538-50.

6 Kim EK, Park CS, Chung WY, Oh KK, Kim DI, Lee JT, et al. New sonographic criteria for recommending fine-needle aspiration biopsy of nonpalpable solid nodules of the thyroid. AJR Am J Roentgenol. 2002 Mar;178(3):68791.
7 Horvath E, Majlis S, Rossi R, Franco C, Niedmann JP, Castro A, et al. An ultrasonogram reporting system for thyroid nodules stratifying cancer risk for clinical management. J Clin Endocrinol Metab. 2009 May;94(5):1748-51.

8 Park JY, Lee HJ, Jang HW, Kim HK, Yi JH, Lee $\mathrm{W}$, et al. A proposal for a thyroid imaging reporting and data system for ultrasound features of thyroid carcinoma. Thyroid. 2009 Nov;19(11):1257-64.

9 Kwak JY, Han KH, Yoon JH, Moon HJ, Son EJ, Park SH, et al. Thyroid imaging reporting and data system for US features of nodules: a step in establishing better stratification of cancer risk. Radiology. 2011 Sep;260(3):8929. 
10 Russ G, Royer B, Bigorgne C, Rouxel A, Bienvenu-Perrard $M$, Leenhardt $L$. Prospective evaluation of thyroid imaging reporting and data system on 4550 nodules with and without elastography. Eur J Endocrinol. 2013 Apr; 168(5):649-55.

11 Ha EJ, Baek JH, Na DG. Risk stratification of thyroid nodules on ultrasonography: current status and perspectives. Thyroid. 2017 Dec; 27(12):1463-8.

12 Shin JH, BaekJH, Chung J, Ha EJ, Kim JH, Lee YH, et al.; Korean Society of Thyroid Radiology (KSThR) and Korean Society of Radiology. Ultrasonography diagnosis and imagingbased management of thyroid nodules: revised Korean Society of Thyroid Radiology consensus statement and recommendations. Korean J Radiol. 2016 May-Jun;17(3):370-95.

13 Gharib H, Papini E, Garber JR, Duick DS, Harrell RM, Hegedüs L, et al.; AACE/ACE/ AME Task Force on Thyroid Nodules. American Association of Clinical Endocrinologists, American College of Endocrinology, and Associazione Medici Endocrinologi medical guidelines for clinical practice for the diagnosis and management of thyroid nodules 2016 update. Endocr Pract. 2016 May;22(5 Supplement 1):622-39.

14 Tessler FN, Middleton WD, Grant EG, Hoang JK, Berland LL, Teefey SA, et al. ACR Thyroid Imaging, Reporting and Data System (TIRADS): White Paper of the ACR TI-RADS Committee. J Am Coll Radiol. 2017 May; 14(5):587-95.

15 Russ G, Bonnema SJ, Erdogan MF, Durante C, Ngu R, Leenhardt L. European Thyroid Association guidelines for ultrasound malignancy risk stratification of thyroid nodules in adults: the EU-TIRADS. Eur Thyroid J. 2017 Sep;6(5):225-37.

16 Lauria Pantano A, Maddaloni E, Briganti SI, Beretta Anguissola G, Perrella E, Taffon C, et al. Differences between ATA, AACE/ACE/ AME and ACR TI-RADS ultrasound classifications performance in identifying cytological high-risk thyroid nodules. Eur J Endocrinol. 2018 Jun;178(6):595-603.

17 Grani G, Lamartina L, Ascoli V, Bosco D, Biffoni M, Giacomelli L, et al. Reducing the number of unnecessary thyroid biopsies while improving diagnostic accuracy: toward the "right" TIRADS. J Clin Endocrinol Metab. 2019 Jan;104(1):95-102.
18 Yoon JH, Lee HS, Kim EK, Moon HJ, Kwak JY. Malignancy risk stratification of thyroid nodules: comparison between the Thyroid Imaging Reporting and Data System and the 2014 American Thyroid Association management guidelines. Radiology. 2016 Mar;278(3): 917-24.

19 Wang Y, Lei KR, He YP, Li XL, Ren WW, Zhao CK, et al. Malignancy risk stratification of thyroid nodules: comparisons of four ultrasound Thyroid Imaging Reporting and Data Systems in surgically resected nodules. Sci Rep. 2017 Sep;7(1):11560.

$20 \mathrm{Xu}$ T, Wu Y, Wu RX, Zhang YZ, Gu JY, Ye $\mathrm{XH}$, et al. Validation and comparison of three newly-released Thyroid Imaging Reporting and Data Systems for cancer risk determination. Endocrine. 2019 May;64(2):299-307.

21 Galen RS. Application of the predictive value model in the analysis of test effectiveness. Clin Lab Med. 1982 Dec;2(4):685-99.

22 Maino F, Forleo R, Martinelli M, Fralassi N, Barbato F, Pilli T, et al. Prospective validation of ATA and ETA sonographic pattern risk of thyroid nodules selected for FNAC. J Clin Endocrinol Metab. 2018 Jun;103(6):2362-8.

23 Trimboli P, Ngu R, Royer B, Giovanella L, Bigorgne C, Simo R, et al. A multicentre validation study for the EU-TIRADS using histological diagnosis as a gold standard. Clin Endocrinol (Oxf). 2019 Aug;91(2):340-7.

24 Alevizaki M, Papageorgiou G, Rentziou G, Saltiki K, Marafelia P, Loukari E, et al. Increasing prevalence of papillary thyroid carcinoma in recent years in Greece: the majority are incidental. Thyroid. 2009 Jul;19(7):74954.

25 Sillery JC, Reading CC, Charboneau JW, Henrichsen TL, Hay ID, Mandrekar JN. Thyroid follicular carcinoma: sonographic features of 50 cases. AJR Am J Roentgenol. 2010 Jan;194(1):44-54.

26 Tugendsam C, Petz V, Buchinger W, SchmollHauer B, Schenk IP, Rudolph K, et al. Ultrasound criteria for risk stratification of thyroid nodules in the previously iodine deficient area of Austria - a single centre, retrospective analysis. Thyroid Res. 2018 May;11(1):3.

27 Ha SM, Kim JK, Baek JH. Detection of malignancy among suspicious thyroid nodules less than $1 \mathrm{~cm}$ on ultrasound with various thyroid image reporting and data systems. Thyroid. 2017 Oct;27(10):1307-15.
28 Choi SH, Kim EK, Kwak JY, Kim MJ, Son EJ. Interobserver and intraobserver variations in ultrasound assessment of thyroid nodules. Thyroid. 2010 Feb;20(2):167-72.

29 Brito JP, Gionfriddo MR, Al Nofal A, Boehmer KR, Leppin AL, Reading C, et al. The accuracy of thyroid nodule ultrasound to predict thyroid cancer: systematic review and metaanalysis. J Clin Endocrinol Metab. 2014 Apr; 99(4):1253-63.

30 Grani G, D’Alessandri M, Carbotta G, Nesca A, Del Sordo M, Alessandrini S, et al. Greyscale analysis improves the ultrasonographic evaluation of thyroid nodules. Medicine (Baltimore). 2015 Jul;94(27):e1129.

31 Reverter JL, Vázquez F, Puig-Domingo M. Diagnostic performance evaluation of a computer-assisted imaging analysis system for ultrasound risk stratification of thyroid nodules. AJR Am J Roentgenol. 2019 Apr;213(1): $1-6$.

32 Moon HJ, Sung JM, Kim EK, Yoon JH, Youk JH, Kwak JY. Diagnostic performance of gray-scale US and elastography in solid thyroid nodules. Radiology. 2012 Mar;262(3): 1002-13

33 Cheng SP, Lee JJ, Lin JL, Chuang SM, Chien MN, Liu CL. Characterization of thyroid nodules using the proposed thyroid imaging reporting and data system (TI-RADS). Head Neck. 2013 Apr;35(4):541-7.

$34 \mathrm{Xu} \mathrm{T,} \mathrm{Gu} \mathrm{JY,} \mathrm{Ye} \mathrm{XH,} \mathrm{Xu} \mathrm{SH,} \mathrm{Wu} \mathrm{Y,} \mathrm{Shao} \mathrm{XY}$ et al. Thyroid nodule sizes influence the diagnostic performance of TIRADS and ultrasound patterns of 2015 ATA guidelines: a multicenter retrospective study. Sci Rep. 2017 Feb;7(1):43183.

35 Castellana M, Castellana C, Treglia G, Giorgino F, Giovanella L, Russ G, et al. Performance of five ultrasound risk stratification systems in selecting thyroid nodules for FNA. A metaanalysis. J Clin Endocrinol Metab. 2020 May; 105(5):dgz170.

36 Grani G, Lamartina L, Cantisani V, Maranghi M, Lucia P, Durante C. Interobserver agreement of various thyroid imaging reporting and data systems. Endocr Connect. 2018 Jan; 7(1):1-7. 